BMJ Open

Diabetes

Research

\& Care

\section{Is glycemia control in Canadians with diabetes individualized? A cross- sectional observational study}

To cite: Coons MJ, Greiver M, Aliarzadeh B, et al. Is glycemia control in Canadians with diabetes individualized? A cross-sectional observational study. BMJ Open Diab Res Care 2017;5:e000316. doi:10.1136/ bmjdrc-2016-000316

Received 24 August 2016 Revised 13 April 2017 Accepted 15 April 2017

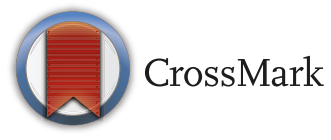

For numbered affiliations see end of article.

Correspondence to

Michelle Greiver;

mgreiver@rogers.com

\section{ABSTRACT}

Objective Diabetes guidelines recommend individualized glycemic targets: tighter control in younger, healthier patients and consideration of more moderate control in the elderly and those with coexisting illnesses. Our objective was to examine whether glycemic control varied by age and comorbidities in Canadian primary care.

Research design and methods Cross-sectional study using data from the electronic medical records of 537 primary care providers across Canada; 30416 patients with diabetes, aged 40 or above, with at least one encounter and one hemoglobin $\mathrm{A} 1 \mathrm{c}(\mathrm{HbA} 1 \mathrm{c})$ measurement between 1 January 2012 and 31 December 2013. The outcome was the most recent $\mathrm{HbA} 1 \mathrm{c}$, categorized into three levels of control: tight $(<7.0 \%$ or $<53 \mathrm{mmol} / \mathrm{mol})$, moderate $(7.0 \%-8.5 \%, 53 \mathrm{mmol} / \mathrm{mol}-69.5 \mathrm{mmol} / \mathrm{mol})$ and uncontrolled $(>8.5 \%$ or $>69.5 \mathrm{mmol} / \mathrm{mol})$. We adjusted for several factors associated with glycemic control including treatment intensity.

Results Younger patients (aged 40-49) were more likely to have moderate as opposed to tight control than the older patients (aged $80+$ ) (OR 1.28; 95\% Cl 1.11 to 1.49 , $p=0.001)$. The youngest were also more likely to have uncontrolled as opposed to moderately controlled glycemia (OR 3.39; $95 \% \mathrm{Cl} 2.75$ to $4.17, \mathrm{p}<0.0001$ ). Patients with no or only one comorbidity were more likely to have moderate as opposed to tight control than those with three or more comorbidities (OR 1.66;95\% Cl 1.46 to $1.90, \mathrm{p}<0.0001$ ). Conclusions Levels of glycemic control, given age and comorbidities appear to differ from guideline recommendations. Research is needed to understand these discrepancies and develop methods to assist providers in personalizing glycemic targets.

\section{INTRODUCTION}

Hemoglobin A1c (HbA1c) represents average blood glucose levels over 3 months and is a valuable indicator of glycemic control in persons with diabetes. ${ }^{2}$ Past guidelines recommended an HbAlc target of $7 \%(53 \mathrm{mmol} / \mathrm{mol})$ or less for most patients. ${ }^{3} 4$ Following the publication of the Veterans Affairs Diabetes Trial (VADT), Action to Control Cardiovascular Risk in Diabetes (ACCORD) and Action in Diabetes and Vascular Disease (ADVANCE)

\section{Significance of this study}

What is already known about this subject?

- Recent guidelines recommend consideration of patients' individual circumstances when setting blood sugar targets. Tighter control, as measured by a lower hemoglobin $\mathrm{A} 1 \mathrm{C}(\mathrm{HbA1C})$, is appropriate for younger, healthier patients and consideration of less intensive control may be advisable for older, sicker patients. Some studies done prior to guideline changes have found that older patients had lower $\mathrm{HbA1c}$ values than younger patients.

What are the new findings?

- Young patients were more likely to have poorly controlled blood sugar while older patients and patients with more illnesses were more likely to have tighter control.

How might these results change the focus of research or clinical practice?

- This study points to possible undertreatment in some younger, healthier patients and overtreatment in some older, sicker patients. Research is needed to understand barriers to setting and implementing individual targets for blood sugar control.

studies in 2008 and $2009^{5-7}$ and concerns about cardiovascular safety associated with intensive control, ${ }^{8}$ recommendations for glycemic targets were reassessed. In 2012, participants in a consensus development conference convened by the American Diabetes Association provided a report recommending higher targets for older persons with diabetes and those in poorer health. ${ }^{9}$ In addition, a position statement was published by the American Diabetes Association and the European Association for the Study of Diabetes supporting a similarly individualized approach. ${ }^{10}$ The most recent American and Canadian Diabetes Association guidelines emphasized less stringent targets (HbAlc $\leq 8.0 \%(64 \mathrm{mmol}$ ) $\mathrm{mol})$ in the USA and $\leq 8.5 \%(69 \mathrm{mmol} / \mathrm{mol})$ 


\section{Research questions}

Why are younger patients more likely to have uncontrolled glycemic levels? Why do older patients and those with more comorbidities attain hemoglobin $\mathrm{A} 1 \mathrm{c}(\mathrm{HbA1c})$ levels in tighter ranges? (A question requiring a qualitative approach.)

$\checkmark$ What could be done about this? How could family physicians and other clinicians looking after patients with diabetes work with patients to determine targets for glycemic goals? Are targets being discussed and agreed upon on?

- Current practice targets for quality improvement (eg, percentage of patients with $\mathrm{HbA1c}$ less than $7 \%$ ) may not consider individualized targets. Is there a system that could be set up to better measure and monitor achieved $\mathrm{HbA1c}$ values compared with appropriate patientcentered targets for patients and populations with diabetes?

in Canada) for older individuals with diabetes living with multiple comorbidities, individuals with extensive cardiovascular disease or patients with a limited life expectancy; more stringent targets $(\leq 6.5 \%)$ could be considered for young patients with recently diagnosed diabetes to further reduce the risk of nephropathy and retinopathy. ${ }^{111}$ In the USA, about half of the patients with diabetes would have a recommended target of $\geq 7 \%$ $(53 \mathrm{mmol} / \mathrm{mol}) .^{12}$

Some studies have shown that older persons may be more likely to have HbAlc values $\leq 7 \%$ (53 mmol/ $\mathrm{mol}$ ) than younger persons ${ }^{1314}$ indicating possible overtreatment in some elders. ${ }^{15}$ Overtreatment in elders was defined as the use of glucose-lowering medications (other than metformin) associated with an increased risk of adverse effects such as hypoglycemia in order to attain tight glycemic control. ${ }^{15}$

A reasonable interpretation of current recommendations is to individualize therapy by focusing efforts to achieve tighter glycemic control in younger, healthier patients and by considering patients' goals and preferences to set individualized, somewhat less stringent HbAlc targets for older patients or those with multiple comorbidities.

The extent to which primary care practitioners in Canada have individualized therapy is unclear. To investigate this issue, we used the Canadian Primary Care Sentinel Surveillance Network (CPCSSN) database. CPCSSN is a nationally representative repository of Canadian primary care electronic medical record (EMR) data updated on a quarterly basis. ${ }^{16}$ As part of a 2013 CPCSSN report, HbA1c levels were found to be lower among older individuals with diabetes compared with younger individuals. ${ }^{17}$ This observation appeared to be inconsistent with the amended practice guidelines and required further investigation.

Our objective was to examine whether glycemic control varied by age and comorbidities in primary care practices across Canada and whether this variation indicated patterns consistent with recommendations to individualize glycemic levels by considering patient characteristics.
RESEARCH DESIGN AND METHODS

\section{Data sources and study population}

We used a retrospective cross-sectional design and applied the The Strengthening the Reporting of Observational Studies in Epidemiology checklist for reporting observational studies. ${ }^{18}$ Routinely collected clinical EMR data contained in the CPCSSN central database was used for this study ${ }^{16}$; CPCSSN is Canada's largest EMR-based chronic disease surveillance system ${ }^{16}$, and it includes data collected from 11 primary care practice-based research networks in eight provinces. Consenting family physicians and other primary care providers participating in CPCSSN contribute de-identified EMR data to a regional CPCSSN repository; patients can opt-out if they choose to do so. Data from all participating networks are aggregated in a single central database. ${ }^{16}{ }^{19}$ The distribution of the CPCSSN patient population is reasonably similar to that of Canadian census. ${ }^{17}$ CPCSSN providers are somewhat younger, more likely to be female and more likely to practice in an academic setting than the source population of Canadian family physicians..$^{20}$ Eighty per cent of Canadian family physicians reported using EMRs in $2014^{21}$; EMR data therefore reflects the majority of primary care records.

We used EMR data extracted as of 31 December 2013 using procedures previously described. ${ }^{16}$ CPCSSN case definition algorithms have been validated against chart audits for eight chronic conditions (diabetes, hypertension, chronic obstructive pulmonary disease, depression, osteoarthritis, dementia, parkinsonism and epilepsy) in multiple sites across Canada. ${ }^{22}$ The case definition for diabetes was shown to have a sensitivity of $96 \%$ and specificity of $97 \% .^{22}$ The seven other validated chronic conditions were used as our measure of comorbidity.

To be included in our final dataset, individuals were required to meet the CPCSSN case definition for diabetes: be at least 40 years of age as of 31 December 2013, have at least one encounter with their practice in 2012 or 2013 and have at least one recorded HbAlc value during the 2 years of interest. We chose a lower bound of 40 years for patient age because of the lower proportion of patients with type 1 diabetes after age 40 . The data do not allow us to reliably categorize the type of diabetes, and this study focused on individuals with type 2 diabetes.

Our primary outcome was the most recent value of HbA1c extracted from the EMR within our observation period. We used HbAlc ranges based on the Canadian Diabetes Association target categories: tight control $(<7 \% \quad(53 \mathrm{mmol} / \mathrm{mol}))$, moderate control $(7 \%-8.5 \%$ $(53-69.5 \mathrm{mmol} / \mathrm{mol}))$ and uncontrolled glycemic levels ( $>8.5 \%(69.5 \mathrm{mmol} / \mathrm{mol})) .{ }^{1}$ We measured factors associated with glycemic control, including demographic variables (age, gender) and clinical variables: medication treatment intensity, comorbidities, body mass index (BMI), blood pressure, lipid values, urine albumin:creatinine ratio (ACR) and number of clinical encounters with primary care provider. 
We estimated medication treatment intensity by measuring the number of diabetes medication classes for each patient. The maximal effect of medication on HbA1c is likely to be seen 3 months or more after a drug has been prescribed. ${ }^{23}$ For this reason, we extracted all diabetes medications prescribed during an observation period extending from 9 months to 3 months prior to the last HbAlc. These drugs were grouped into medication classes (metformin, sulfonylureas, thiazolidinediones, glucagon-like peptide-1 agonists, dipeptidyl peptidase 4 inhibitors, insulins) following the Canadian and American Diabetes Association's recommendations for classification. ${ }^{23}$ In some Canadian provinces, refills for insulin can be obtained without a prescription ${ }^{24}$; for this class of medication, we considered a patient to be on an insulin if there was evidence of any prescription for this drug, with the latest observation being at least 3 months prior to the reference $\mathrm{HbAlc}$ measure.

Each class of medication decreases HbA1c by $0.5 \%-$ $1.5 \% \quad(5.5 \mathrm{mmol} / \mathrm{mol}-16.4 \mathrm{mmol} / \mathrm{mol}),{ }^{1}$ with the exception of insulin, which does not have a ceiling effect. We summed the number of classes of diabetes medications present during the observation period: patients in group 0 (lowest intensity) had no diabetes prescriptions, those in group 1 had one class of medications prescribed, those in group 2 had two classes and those in group 3 (highest intensity) had three or more classes. We classified all patients on insulin as being in the highest intensity group (group 3). This is similar to the approach taken by De Vries and colleagues to classify potential overtreatment of glycemia. ${ }^{25}$

\section{Statistical analysis}

All statistical analyses were conducted using SAS software V.9.3 (SAS Institute). Our outcome of interest was the most recent $\mathrm{HbAlc}$ measured for each patient, grouped into glycemic control ranges (tight control, moderate control, uncontrolled). We used contingency tables to describe bivariate associations between our categorical response variable (HbAlc control) and our categorical covariates (age group, gender, number of comorbidities, systolic blood pressure, low density lipoprotein, urine ACR, BMI, medication treatment intensity and number of primary care encounters). We employed a random intercept multinomial logistic regression model to model these data. The multinomial logistic regression model accounts for the discrete nature of our response variable, whereas the inclusion of a random intercept in the linear predictor of this model is used to account for the positive correlation between responses arising from the same cluster (here the same physician). The main focus of this analysis is to estimate the impact of age and comorbidities on the probability of being included into each glycemic range, after controlling for the other variables in the models.

This study was reviewed and approved by the Research Ethics Board (REB) at the University of Toronto. CPCSSN has received REB approval from Health Canada and each host university for all participating practice-based research networks. All participating primary care providers have provided written informed consent for the collection and analysis of their EMR data.

\section{RESULTS}

Data from 537 primary care providers were included in our dataset. There were 48143 patients aged 40 and above with diabetes and $30416(63.2 \%)$ had been seen at least once and had at least one HbAlc during the 2 years of interest; these patients comprised the final sample included in this study.

Patient characteristics and $\mathrm{HbA1c}$ ranges are presented in table 1.

The proportion of individuals within each age range by number of classes of medication prescribed is presented in table 2. Patients $(7.1 \%)$ in the oldest age category were receiving high intensity treatment (three or more classes of medications or insulin), while $11.4 \%$ of patients in the youngest age category were in the high medication intensity group. The association between age and medication intensity was significant $(\mathrm{p}<0.0001)$.

Table 3 presents the results of the bivariate analyses. We examined three ranges of glycemic control; therefore, there are three comparisons (or models) of interest: (1) moderate versus tight glycemic control, (2) uncontrolled versus tight glycemic control and (3) uncontrolled versus moderate glycemic control. Increasing age and increasing number of comorbid conditions were associated with higher ORs of being in the tight or moderate glycemic ranges.

Table 4 presents the results of the multivariate analyses. We controlled for all variables in table 3, with the exception of urine albumin to creatinine ratio as it was missing in $51 \%$ of the sample.

After adjusting for other covariates including medication intensity, younger patients (aged 40-49) were more likely than older patients $(80+)$ to have moderate glycemic control compared with tight glycemic control (OR 1.28; 95\% CI 1.11 to $1.49, \mathrm{p}=0.001$ ). Younger patients (aged 40-49) were more likely than the older patients $(80+)$ to have uncontrolled glycemic control compared with moderate glycemic control (OR 3.39; 95\% CI 2.75 to $4.17, \mathrm{p}<0.0001)$. In other words, younger patients were more likely to have uncontrolled glycemia than older patients.

Patients with fewer comorbidities $(0-1)$ were more likely than patients with multiple comorbidities $(3+)$ to have moderate glycemic control compared with tight glycemic control (OR 1.66; 95\% CI 1.46 to $1.90, \mathrm{p}<0.0001$ ).

Lastly, increasing medication intensity was associated with poorer glycemic control, particularly for younger people. Patients on intensive medication management had an OR of 5.43 of being in the moderate control as opposed to tight control (95\% CI 4.78 to 6.17 , $\mathrm{p}<0.0001$ ). After controlling for all variables, younger people receiving intensive medication management had a mean 
Table 1 Patient characteristics and $\mathrm{HbA} 1 \mathrm{c}$ ranges

\begin{tabular}{|c|c|c|c|c|c|}
\hline $\begin{array}{l}\text { Patient } \\
\text { characteristics }\end{array}$ & Variable & $\begin{array}{l}\mathrm{N} \text { (\% of } \\
\text { patients within } \\
\text { characteristic } \\
\text { group) }\end{array}$ & $\begin{array}{l}\text { Tight control: } \\
\text { HbA1c }<7 \%, \mathrm{~N}(\% \\
\text { of patients within } \\
\text { HbA1c control } \\
\text { range) }\end{array}$ & $\begin{array}{l}\text { Moderate control: } \\
\text { HbA1c } 7 \%-8.5 \% \text {, } \\
\mathrm{N}(\% \text { of patients } \\
\text { within HbA1c } \\
\text { control range) }\end{array}$ & $\begin{array}{l}\text { Not controlled: } \\
\text { HbA1c }>8.5 \% \text {, } \\
\text { N ( } \% \text { of patients } \\
\text { within HbA1c } \\
\text { control range) }\end{array}$ \\
\hline $\begin{array}{l}\text { All patients in } \\
\text { sample }\end{array}$ & & 30416 & 16705 (54.92) & $9298(30.57)$ & $4413(14.51)$ \\
\hline \multirow{5}{*}{$\begin{array}{l}\text { Age range in } \\
\text { years }\end{array}$} & $40-49$ & $2506(8.24)$ & $1162(46.37)$ & $687(27.41)$ & 657 (26.22) \\
\hline & $50-59$ & $6253(20.56)$ & $3123(49.94)$ & $1833(29.31)$ & $1297(20.74)$ \\
\hline & $60-69$ & 9041 (29.72) & 4902 (54.22) & $2816(31.15)$ & 1323 (14.63) \\
\hline & 70-79 & 7545 (24.80) & 4414 (58.53) & 2420 (32.07) & 709 (9.04) \\
\hline & $80+$ & 5073 (16.68) & 3104 (61.19) & $1542(30.40)$ & $427(8.42)$ \\
\hline \multirow{3}{*}{$\begin{array}{l}\text { Number of } \\
\text { comorbidities }^{*}\end{array}$} & $0-1$ & 6783 (22.30) & 3398 (50.10) & 2197 (32.39) & 1188 (17.51) \\
\hline & $2-3$ & 20578 (67.6) & 11430 (55.55) & $6268(30.46)$ & $2880(13.99)$ \\
\hline & 4 or more & 3055 (10.04) & $1877(61.44)$ & $833(27.27)$ & 345 (11.29) \\
\hline \multirow[t]{3}{*}{ Gender } & Male & $15942(52.41)$ & 8532 (53.53) & 4945 (31.02) & $2463(15.45)$ \\
\hline & Female & 14475 (47.59) & $8172(56.46)$ & $4353(30.07)$ & $1950(13.47)$ \\
\hline & Missing & $1(0)$ & - & - & - \\
\hline \multirow[t]{3}{*}{$\mathrm{sBP}>130 \mathrm{~mm} \mathrm{Hg}$} & No & $15821(52.02)$ & 8985 (56.79) & $4662(29.47)$ & $2174(13.74)$ \\
\hline & Yes & $12338(40.56)$ & $6601(53.51)$ & $3870(31.36)$ & 1867 (15.13) \\
\hline & Missing & 2257 (7.42) & 1119 (49.58) & 766 (33.94) & $372(16.48)$ \\
\hline \multirow[t]{3}{*}{ LDL in $\mathrm{mmol} / \mathrm{L}$} & $<2$ & 14018 (46.09) & $7451(56.15)$ & $4738(33.80)$ & 1829 (13.05) \\
\hline & $\geq 2$ & $14190(46.65)$ & 8194 (57.75) & 3877 (27.32) & 2119 (14.93) \\
\hline & Missing & 2208 (7.26) & $1060(48.01)$ & $683(30.93)$ & 465 (21.06) \\
\hline \multirow{3}{*}{$\begin{array}{l}\text { Urine albumin to } \\
\text { creatinine ratio }\end{array}$} & $<2$ & 8328 (27.38) & 4452 (53.46) & 2725 (32.72) & $1151(13.82)$ \\
\hline & $\geq 2$ & $6570(21.60)$ & $2944(44.81)$ & $2273(34.60)$ & 1353 (20.59) \\
\hline & Missing & $15518(51.02)$ & 9309 (59.99) & $4300(27.71)$ & 1909 (12.30) \\
\hline \multirow[t]{4}{*}{$\mathrm{BMI}$} & $<25$ & 3320 (10.92) & $2039(61.42)$ & $890(26.81)$ & 391 (11.78) \\
\hline & $25-29.9$ & $7564(24.87)$ & 4426 (58.52) & $2270(30.01)$ & $868(11.47)$ \\
\hline & $\geq 30$ & 12632 (41.53) & 6699 (53.04) & $3924(31.06)$ & 2009 (15.90) \\
\hline & Missing & 6900 (22.69) & 3541 (51.32) & 2214 (32.09) & 1145 (16.59) \\
\hline \multirow{3}{*}{$\begin{array}{l}\text { Number of } \\
\text { encounters in the } \\
\text { past } 2 \text { years }\end{array}$} & $1-5$ & 4012 (13.19) & 2243 (55.91) & $1144(28.51)$ & 625 (15.58) \\
\hline & $6-16$ & 15199 (49.97) & 8603 (56.61) & 4577 (30.11) & 2019 (13.28) \\
\hline & 17 or more & 11205 (36.84) & 5859 (52.29) & 3577 (31.92) & 1769 (15.79) \\
\hline \multirow{4}{*}{$\begin{array}{l}\text { Number of } \\
\text { classes of } \\
\text { medication } \\
\text { prescribed }\end{array}$} & $\begin{array}{l}0 \text { (no diabetic } \\
\text { medications) }\end{array}$ & 19353 (63.62) & 11990 (61.95) & $5004(25.86)$ & 2359 (12.19) \\
\hline & $\begin{array}{l}1 \text { ( } 1 \text { class of } \\
\text { medications) }\end{array}$ & 5991 (19.70) & $3295(55.00)$ & $2070(34.55)$ & $626(10.45)$ \\
\hline & $\begin{array}{l}2 \text { ( } 2 \text { classes of } \\
\text { medications) }\end{array}$ & $2086(6.86)$ & 780 (37.39) & 912 (43.72) & 394 (18.89) \\
\hline & $\begin{array}{l}3 \text { ( } 3 \text { classes of } \\
\text { medications or } \\
\text { insulin) }\end{array}$ & 2986 (9.82) & $640(21.43)$ & $1312(43.94)$ & 1034 (34.63) \\
\hline
\end{tabular}

*Includes the CPCSSN validated comorbidities only (hypertension, chronic obstructive pulmonary disease, depression, osteoarthritis, dementia, epilepsy, Parkinson's disease).

BMI, body mass index; HbA1c, hemoglobin A1c; LDL, low density lipoprotein; sBP, systolic blood pressure. 
Table 2 Proportion of patients by number of classes of diabetes medications prescribed within each age range

\begin{tabular}{|c|c|c|c|c|}
\hline \multirow[b]{2}{*}{ Age range in years } & \multicolumn{4}{|c|}{ Number of classes of medication prescribed } \\
\hline & $\begin{array}{l}0 \text { (no diabetic } \\
\text { medications) }\end{array}$ & $\begin{array}{l}1 \text { (1 class of } \\
\text { medications) }\end{array}$ & $\begin{array}{l}2 \text { ( } 2 \text { classes of } \\
\text { medications) }\end{array}$ & $\begin{array}{l}3 \text { ( } 3 \text { classes of } \\
\text { medications or insulin) }\end{array}$ \\
\hline $50-59$ & $3945(63.09)$ & $1245(19.91)$ & $422(6.75)$ & $641(10.25)$ \\
\hline $60-69$ & $5580(61.72)$ & $1840(20.35)$ & $663(7.33)$ & $958(10.60)$ \\
\hline $80+$ & $3371(66.45)$ & $1041(20.52)$ & $299(5.89)$ & $362(7.14)$ \\
\hline
\end{tabular}

HbAlc of $8.71 \%(72 \mathrm{mmol} / \mathrm{mol})$ and $95 \% \mathrm{CI} 8.42$ to 8.99 (69 $\mathrm{mmol} / \mathrm{mol}-75 \mathrm{mmol} / \mathrm{mol})$, while the oldest had a mean $\mathrm{HbAlc}$ of $7.70 \%(61 \mathrm{mmol} / \mathrm{mol})$ and $95 \%$ CI 7.52 to $7.88(59-63 \mathrm{mmol} / \mathrm{mol})$.

A subgroup analysis was done by removing patients not on any medications. Younger patients (aged 40-49) were more likely than older patients $(80+)$ to have moderate glycemic control compared with tight glycemic control but this was no longer significant (OR 1.09; 95\% CI 0.84 to $1.41, \mathrm{p}=0.5$ ). Younger patients (aged 40-49) were more likely than older patients $(80+)$ to have uncontrolled glycemic levels compared with moderate glycemic levels (OR 2.77; 95\% CI 2.00 to 3.84, $\mathrm{p}<0.0001$ ).

\section{CONCLUSIONS}

Guidelines currently recommend tighter glycemic control for younger patients and those with fewer comorbidities and consideration of more moderate control in older patients and those with more comorbidities. ${ }^{12}$ In this study, we found that the inverse was present. The younger patients were more likely to have poorly controlled glycemic levels while the older patients were more likely to have tight rather than moderate control. Those with more comorbidities were more likely to have tight rather than moderate control than those with fewer comorbidities. High medication intensity was associated with poorer glycemic control; this was more pronounced in younger patients. These effects remained after controlling for gender, cardiovascular risk factors or frequency of healthcare contacts.

The balance between risks and benefits associated with glycemic control changes with age. Glycemic control is particularly important at younger ages because of the cumulative effects of poor glycemic control on microvascular and macrovascular complications. Conversely, the risks of tighter control and polypharmacy may be greater in the elderly. Our findings highlight an imbalance, with relative undertreatment of glycemia in some younger patients coupled with possible overtreatment of some older patients.

As part of choosing wisely, the American Geriatrics Society recommended against tight glycemic control and caution with prescriptions of medications other than metformin in most older patients. ${ }^{26}$ We found that a considerable proportion of older patients in Canada were receiving multiple classes of glucose-lowering medications. Further studies exploring appropriate glycemic targets in the context of ageing, multimorbidity and polypharmacy could be of benefit.

A recent study found that patients with multiple comorbidities had lower HbAlc values than those without comorbidities. ${ }^{27}$ We found as well that a greater number of comorbidities was associated with a greater likelihood of having tight glycemic control; this persisted after adjustment for multiple other factors, including increasing age. A greater number of healthcare contacts due to complex or multiple conditions may be a contributing factor, as an increase in the number of visits could afford more opportunities to manage glycemia or create an increased sense of patient accountability for their self-management efforts. In one study, HbA1c values were similar in patients with severe mental illnesses and those without; the authors speculated that this could be due to more frequent healthcare contacts for those with mental illness. ${ }^{28}$ In our study, however, we found no association between encounter frequency in primary care and glycemic control.

The ACCORD, ADVANCE and VADT studies found that the impact of tight glycemic control on short-term macrovascular outcomes was uncertain. ${ }^{5-7}$ A reduction of about $15 \%$ in long-term macrovascular outcomes (largely due to fewer major cardiovascular events) was recently found after extended observational follow-up of the VADT, ACCORD and UK Prospective Diabetes Study (UKPDS) studies, with inconsistent effects on mortality. $^{29-31}$

Recent studies have found improvements in cardiovascular outcomes and reduced mortality with the addition of newer drugs, specifically a glucagon-like peptide-1 agonist, liraglutide, ${ }^{32}$ and a sodium-glucose cotransporter 2 inhibitor, empagliflozin. ${ }^{33}$ These benefits occurred despite relatively small reductions in HbAlc when compared with usual care. The findings suggest that medication effects other than those associated with improved glycemic control may be predictive of cardiovascular outcomes. ${ }^{33}$ The results continue to support an individualized approach to HbAlc targets, taking into account life expectancy, as well as risks of hypoglycemia, 


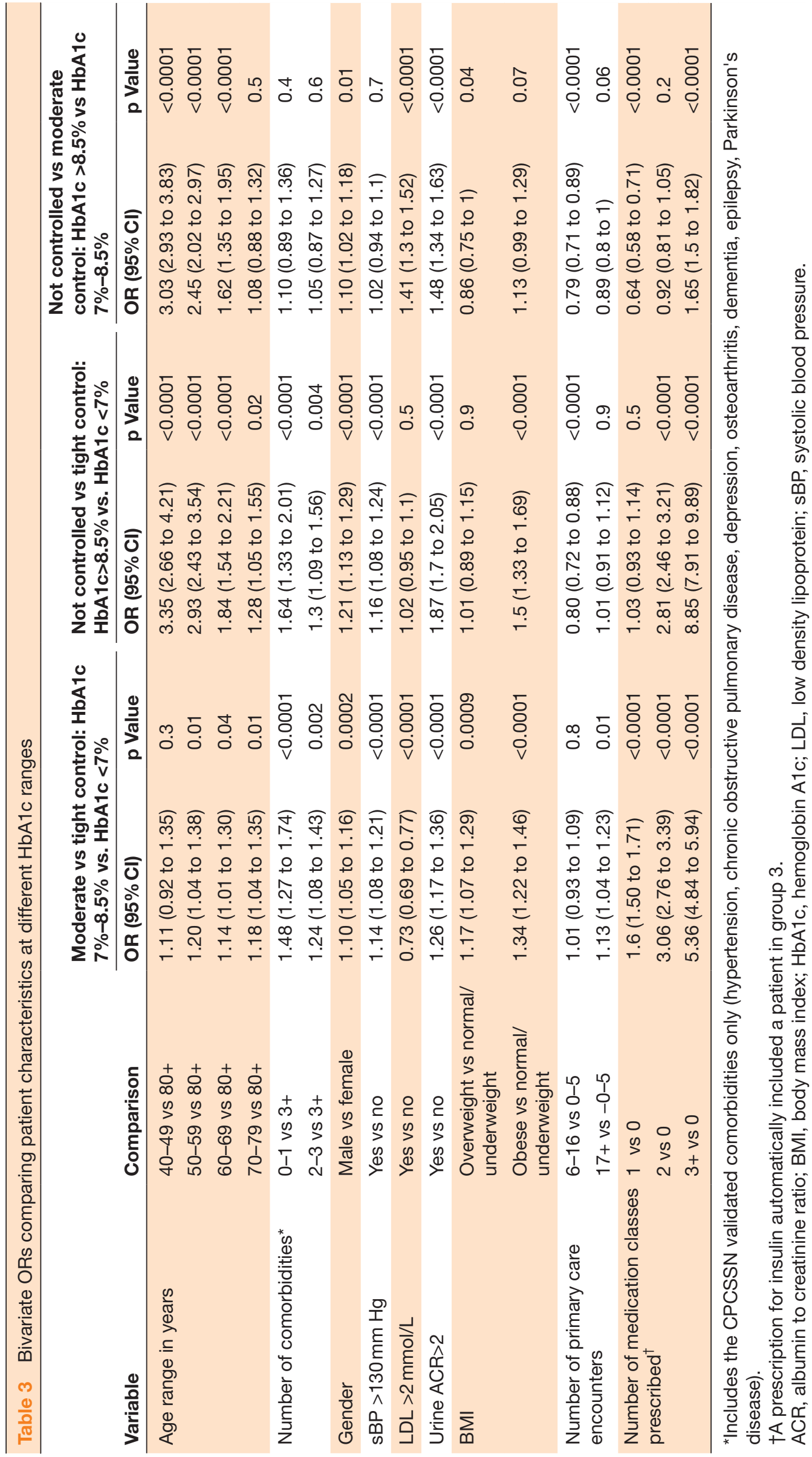




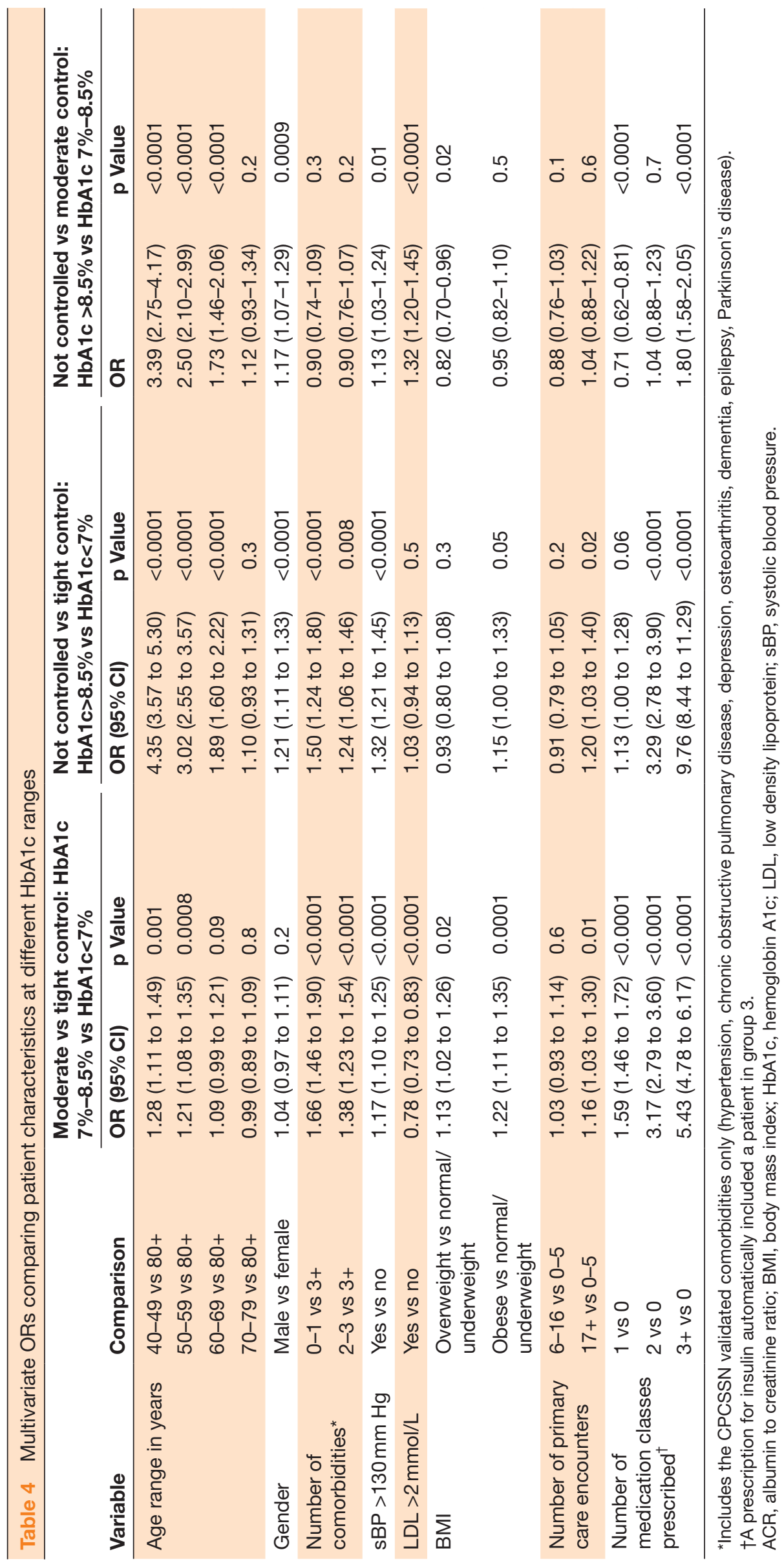


potential side effects and overall burden of medications all of which tend to be greater in older patients and those with multimorbidities.

The care of patients with diabetes can be complex due to advancing age and multiple coexisting conditions, each associated with guideline recommendations that are not always concordant. A discussion of goals and preferences should occur with patients, and their preferences should be considered when developing personal glycemic targets. ${ }^{34}$ Further research is needed to better understand why younger adults and those with few comorbidities experience uncontrolled glycemic levels and to explore glycemic goals and medication intensity for elderly patients. Interventional studies, including enhanced prescribing for those benefiting from lower targets or de-prescribing for those identified as needing less intensive glycemic targets ${ }^{35}$ could address the imbalance identified in this study. Clinical decision support systems could also be implemented in EMRs to assist in identifying appropriate targets for different patient populations.

The study had several strengths. It reflected data from routine clinical care for patients with diabetes in community-based primary care. We included a large sample of both patients and primary care providers from multiple settings across Canada. Therefore, this study reasonably reflects current clinical practices for individuals with diabetes receiving primary care in Canada. Data were extracted from multiple different EMR platforms, accounting for a variety of EMR-specific data entry processes by clinicians. Despite these strengths, this study includes several shortcomings. This was a convenience sample of primary care practices that contributed EMR data to CPCSSN, rather than a random sample from the population of all primary care practices. Recent efforts to explore the representativeness of CPCSSN data to the Canadian population of primary care practices have shown that participating physicians are slightly younger and likely to be female compared with the population of physicians who have responded to the National Physician Survey. ${ }^{17}$ The cross-sectional design that was used in this study does not permit us to make causal inferences about the direction of the relationships between HbA1c, age and medications in this population. We were unable to collect several variables relevant to individualized glycemic targets, as these are not available in the EMR or are generally not collected in a manner that permits extraction and standardization of data. These variables include hypoglycemic events, diabetes duration, comorbid conditions other than those with CPCSSN validated case definitions and data on life expectancy. Data on ethnicity are currently very limited in Canadian EMRs, so these were not included in our study. Our data does not allow us to differentiate between patients with type 1 and type 2 diabetes. Lastly, it is possible that survivorship bias may have affected our results; patients with very poor glycemic control may have died at an earlier age. However, the association between efforts to decrease
HbA1c values and improvements in mortality remains uncertain.

In conclusion, we found that the younger patients were less likely to have tight glycemic control while the older were less likely to have moderate control. Patients with a greater number of comorbidities were more likely to have tight control than those with fewer health conditions. Consequently, there appears to be discrepancies between clinical practice and guideline recommendations to develop individualized HbA1c targets by considering age and number of comorbidities.

\section{Author affiliations}

${ }^{1}$ Department of Family and Community Medicine, Faculty of Medicine, University of Toronto, Toronto, Canada

${ }^{2}$ Medical Bariatric Program, St. Joseph's Healthcare Hamilton, Hamilton, Canada

${ }^{3}$ Department of Psychology, Faculty of Health, York University, Toronto, Canada

${ }^{4}$ North York Family Health Team, Toronto, Canada

${ }^{5}$ Canadian Primary Care Sentinel Surveillance Network, Kingston, Canada

${ }^{6}$ Department of Family and Community Medicine, North York General Hospital,

Toronto, Canada

${ }^{7}$ Primary Care and Population Health, Institute for Clinical Evaluative Sciences, Toronto, Canada

${ }^{8}$ Department of Community Health Sciences, Cumming School of Medicine, University of Calgary, Toronto, Canada

${ }^{9}$ Department of Medicine, Division of Endocrinology \& Metabolism, St. Michael's Hospital, Toronto, Canada

${ }^{10}$ Department of Family and Community Medicine, Li Ka Shing Knowledge Institute, St. Michael's Hospital, Toronto, Canada

${ }^{11}$ Department of Family Medicine, Markham Stouffville Hospital, Toronto, Canada

Correction notice This paper has been amended since it was published Online First. Owing to a scripting error, some of the publisher names in the references were replaced with 'BMJ Publishing Group'. This only affected the full text version, not the PDF. We have since corrected these errors and the correct publishers have been inserted into the references.

Contributors MJC and MG contributed to the conception and design. BA was responsible for the acquisition of data. CM, BA and RM contributed substantially to the analysis of data. CHY provided content-specific expertise on diabetes. MJC and MG drafted the initial version of the article. All authors contributed to the interpretation of data. All authors reviewed and revised the article for important intellectual content and gave final approval of the version to be published. MG is the guarantor of this work and, as such, had full access to all the data in the study and takes responsibility for the integrity of the data and the accuracy of the data analysis.

Funding The Canadian Primary Care Sentinel Surveillance Network was a committee of the College of Family Physicians of Canada and was funded through a contribution agreement with the Public Health Agency of Canada.

Disclaimer The views expressed herein do not necessarily represent the views of the Public Health Agency of Canada.

Competing interests MG holds an investigator award from the Department of Family and Community Medicine, University of Toronto.

Patient consent This is an observational study with no patient intervention and no patient identification.

Ethics approval University of Toronto.

Provenance and peer review Not commissioned; externally peer reviewed. Data sharing statement Data are from a nationally representative Canadian repository of primary care electronic medical record data, the Canadian Primary Care Sentinel Surveillance Network (CPCSSN, cpcssn.ca). CPCSSN data are available to researchers as outlined in the process available on the website.

Open Access This is an Open Access article distributed in accordance with the Creative Commons Attribution Non Commercial (CC BY-NC 4.0) license, which permits others to distribute, remix, adapt, build upon this work non-commercially, and license their derivative works on different terms, provided the original work is properly cited and the use is non-commercial. See: http://creativecommons.org/ licenses/by-nc/4.0/ 
(c) Article author(s) (or their employer(s) unless otherwise stated in the text of the article) 2017. All rights reserved. No commercial use is permitted unless otherwise expressly granted.

\section{REFERENCES}

1. Cheng AY; Canadian Diabetes Association Clinical Practice Guidelines Expert Committee. Canadian Diabetes Association 2013 clinical practice guidelines for the prevention and management of diabetes in Canada. Introduction. Can J Diabetes 2013;37 Suppl 1:S1-S212.

2. American Diabetes Association. Standards of medical care in diabetes. Diabetes Care 2014;2014:S14-S80.

3. Canadian Diabetes Association 2008. Clinical practice guidelines for the prevention and management of diabetes in Canada. Can J Diabetes2008;32.

4. American Diabetes Association. Standards of medical care in diabetes - 2011. Diabetes Care 2011;34 Suppl 1:S11-S61.

5. Patel A, MacMahon S, Chalmers J, et al. Intensive blood glucose control and vascular outcomes in patients with type 2 diabetes. $N$ Engl J Med 2008;358:2560-72.

6. Duckworth W, Abraira C, Moritz T, et al. Glucose control and vascular complications in veterans with type 2 diabetes. $N$ Engl J Med 2009;360:129-39.

7. Gerstein HC, Miller ME, Byington RP, et al. Action to control cardiovascular risk in Diabetes Study Group: effects of intensive glucose lowering in type 2 diabetes. $N$ Engl J Med 2008;358:2545-59.

8. Boussageon R, Bejan-Angoulvant T, Saadatian-Elahi M, et al. Effect of intensive glucose lowering treatment on all cause mortality, cardiovascular death, and microvascular events in type 2 diabetes: meta-analysis of randomised controlled trials. BMJ 2011;343:d4169.

9. Kirkman MS, Briscoe VJ, Clark N, et al. Diabetes in older adults. Diabetes Care 2012;35:2650-64.

10. Inzucchi SE, Bergenstal RM, Buse JB, et al. Management of hyperglycemia in type 2 diabetes: a patient-centered approach: position statement of the American Diabetes Association (ADA) and the European Association for the study of Diabetes (EASD). Diabetes Care 2012;35:1364-79.

11. Fox CS, Golden SH, Anderson C, et al. Update on prevention of cardiovascular disease in adults with type 2 diabetes mellitus in light of recent evidence: a scientific statement from the American Heart Association and the American Diabetes Association. Diabetes Care 2015;38:1777-803.

12. Laiteerapong $\mathrm{N}$, John PM, Nathan AG, et al. Public health implications of recommendations to individualize glycemic targets in adults with diabetes. Diabetes Care 2013;36:84-9.

13. Teoh $\mathrm{H}$, Braga MF, Casanova A, et al. Patient age, ethnicity, medical history, and risk factor profile, but not drug insurance coverage, predict successful attainment of glycemic targets: Time 2 Do More Quality Enhancement Research Initiative (T2DM QUERI). Diabetes Care 2010;33:2558-60.

14. Stark Casagrande S, Fradkin JE, Saydah SH, et al. The prevalence of meeting $\mathrm{A} 1 \mathrm{C}$, blood pressure, and LDL goals among people with diabetes, 1988-2010. Diabetes Care 2013;36:2271-9.

15. Lipska KJ, Ross JS, Miao Y, et al. Potential overtreatment of diabetes mellitus in older adults with tight glycemic control. JAMA Intern Med 2015;175:356-62.

16. Birtwhistle R, Keshavjee $\mathrm{K}$, Lambert-Lanning A, et al. Building a pan-Canadian primary care sentinel surveillance network: initial development and moving forward. J Am Board Fam Med 2009;22:412-22.
17. Primary health care intelligence: 2013 progress report of the Canadian primary care Sentinel Surveillance Network (CPCSSN). Kingston, Ontario: Queen's University, 2013.

18. von Elm E, Altman DG, Egger M, et al. The Strengthening the Reporting of Observational Studies in Epidemiology (STROBE) statement: guidelines for reporting observational studies. Int J Surg 2014;12:1495-9.

19. Birtwhistle RV. Canadian primary care Sentinel Surveillance Network: a developing resource for family medicine and public health. Can Fam Physician 2011;57:1219-20.

20. Queenan JA, Williamson T, Khan S, et al. Representativeness of patients and providers in the canadian primary care Sentinel Surveillance Network: a cross-sectional study. CMAJ Open 2016;4:E28-E32

21. National Physician Survey 2014, capture of patient information (article online). 2014 http://nationalphysiciansurvey.ca/wp-content/ uploads/2014/09/2014-FPGP-EN-Q7.pdf (accessed 06 Apr 2015).

22. Williamson T, Green ME, Birtwhistle R, et al. Validating the 8 CPCSSN case definitions for chronic disease surveillance in a primary care database of electronic health records. Ann Fam Med 2014;12:367-72

23. Harper W, Clement M, Goldenberg R, et al. Canadian Diabetes Association 2013. Clinical practice guidelines for the prevention and mManagement of diabetes in Canada: pharmacologic management of type 2 diabetes. Can J Diabetes 2013:S61-S68.

24. Drug schedules to the pharmacy operations and drug scheduling act of British Columbia (article online). 2012 http://library.bcpharmacists. org/D-Legislation_Standards/D-4_Drug_Distribution/5012-Drug_ Schedules Regulation.pdf (accessed 17 July 2015).

25. de Vries ST, Voorham J, Haaijer-Ruskamp FM, et al. Potential overtreatment and undertreatment of diabetes in different patient age groups in primary care after the introduction of performance measures. Diabetes Care 2014;37:1312-20.

26. Choosing wisely: American Geriatrics Society (article online). 2015 http://www.choosingwisely.org/clinician-lists/american-geriatricssociety-medication-to-control-type-2-diabetes/ (accessed 10 Aug 2015).

27. Lin PJ, Kent DM, Winn A, et al. Multiple chronic conditions in type 2 diabetes mellitus: prevalence and consequences. Am J Manag Care 2015;21:e23-34.

28. Krein SL, Bingham CR, McCarthy JF, et al. Diabetes treatment among VA patients with comorbid serious mental illness. Psychiatr Serv 2006;57:1016-21.

29. Hayward RA, Reaven PD, Wiitala WL, et al. Follow-up of glycemic control and cardiovascular outcomes in type 2 diabetes. $N$ Engl $J$ Med 2015;372:2197-206.

30. Gerstein HC, Miller ME, Ismail-Beigi F, et al. Effects of intensive glycaemic control on ischaemic heart disease: analysis of data from the randomised, controlled ACCORD trial. Lancet 2014;384:1936-41.

31. Holman RR, Paul SK, Bethel MA, et al. 10-year follow-up of intensive glucose control in type 2 diabetes. N Engl J Med 2008;359:1577-89.

32. Marso SP, Daniels GH, Brown-Frandsen K, et al. Liraglutide and cardiovascular outcomes in type 2 diabetes. $N$ Engl J Med 2016;375:311-22.

33. Zinman B, Wanner C, Lachin JM, et al. Empagliflozin, cardiovascular outcomes, and mortality in type 2 diabetes. $N$ Engl J Med 2015;373:2117-28.

34. Vijan S, Sussman JB, Yudkin JS, et al. Effect of patients' risks and preferences on health gains with plasma glucose level lowering in type 2 diabetes mellitus. JAMA Intern Med 2014;174:1227-34.

35. Boulin M, Diaby V, Tannenbaum C. Preventing unnecessary costs of drug-induced hypoglycemia in older adults with type 2 diabetes in the United States and Canada. PLoS One 2016;11:e0162951. 